\title{
Ayurveda vs COVID-19: Developing an Influence towards Good Health
}

\author{
Jyoti Prakash ${ }^{1}$, Aman Mittal ${ }^{2 *}$, Amit Kumar Sen ${ }^{3}$
}

${ }^{1}$ Research Scholar, School of Hospitality, GD Goenka University, Gurgaon, Haryana, India

${ }^{2}$ Research Scholar, School of Medical and Applied science, GD Goenka University, Gurgaon, Haryana, India

${ }^{3}$ Assistant Professor, Global Institute of Pharmaceutical Education and Research, Kashipur, Uttarakhand, India

DOI: $10.36347 /$ sjams.2021.v09i01.012

| Received: 22.12.2020 | Accepted: 09.01.2021 | Published: 13.01.2021

*Corresponding author: Aman Mittal

Abstract

The existence of Ayurveda has been since 1000 B.C.E since the implication was in medicine and surgery where a holistic method was used to maintain the proper wellbeing of humanity. The translation of the "Ayurveda" literates to the science of life where it shows the combination of three elements, i.e. vatta, pitta, and Kapha. These three elements constitute the human body and also balances its forces. In the ancient period, the sages who followed the veda's constitute the Ayurveda in various concepts such as Paatra Shuddhi, Paaka Shuddhi, and Padartha Shuddhi which they followed in their cooking process to have a pure and balance within their body to stay fit and healthy. Since then, the implication of Ayurveda has been considered to be unique and adopted by several individuals to maintain a stable and calm in their mind and soul. But due to the outbreak of coronavirus, it was said that the implementation of the traditional remedy, i.e., Ayurveda would help in curing the diseases and delevating the symptoms of the virus which were: fever, tiredness, dry cough, aches and pains, nasal congestion, runny nose, diarrhea, and sore throat. These were the major traits seen by medical professionals during the treatment course. The Ayurveda has various medication which has tremendous results without giving any side-effects but the most common which everyone knows is the tulsi (holy basil) which has a tremendous multi-modal therapeutic effect towards effective prevention and proper management towards the COVID-19 effect. Apart from the use of tulsi, turmeric also has a very effective medicinal touch to every medication; it is told that a glass of lukewarm turmeric water or by putting turmeric in the milk helps in maintaining a balance in the body cycle. It is always said that to have a proper Vedic lifestyle everyone should follow five practices of Din-acharya which means the four elements that one should follow to complete the daily cycle; walking, sleeping, working and meditation to have good health during the COVID-19 situation.

Keywords: Ayurveda, Holistic health, Covid-19 symptoms, Traditional medication, Lifestyle etc.

Copyright $(\mathcal{2 0 2 1}$ The Author(s): This is an open-access article distributed under the terms of the Creative Commons Attribution 4.0 International License (CC BY-NC 4.0) which permits unrestricted use, distribution, and reproduction in any medium for non-commercial use provided the original author and source are credited.

\section{INTRODUCTION}

India, a country with a very rich usage of medicinal plants for treatment for many decades. The Indian medical science shows the implication of Ayurveda, Unani, and Siddha medicine from the period 'Sushruta', father of surgery and plastic surgery, who gaveancient India a new phase tothe treatment using ayurvedic and surgical practices which helped the country to flourish itself into the medicinal usage into a new phase wherethe cure was done by using natural elements to improve thephase of Ayurvedic scienceby giving the human beings a holistic life bypreventing diseases and introducing new medicine to induce the interest of others to have a change towards having a better lifestyle in the emerging new era by performing natural treatment and remedies [1-3].
The basic difference between Ayurveda and Allopathic medicine is that western medicine focuses on the disease and uses drugs and surgery to rid the disease from the body whereas Ayurvedahelps in maintaining a systematic life cycle into the everyday daily routine. When there is less stress and the flow of energy within a person is balanced the body's natural defense system will be strong and can work more easily. Ayurveda is based on the principle of maintaining a balance between the body and mind. It is found that disease-like memory loss, osteoporosis, diabetic wound for which there is insufficient medicine available in modern therapy [4].

India with higher usage of ayurvedic practices looks to provide growth of Ayurvedic in the market by the export of Ayurvedic medicines. The fundamental principles of the relationship between man and nature were more or less the same in all the medical systems 
Jyoti Prakash et al.,; Sch J App Med Sci, Jan, 2021; 9(1): 65-69

but their approach in therapy was different. It is said that the Ayurveda originated from Brahma the God of Creation. Vedic knowledge reveals that there was a keen observation by the priests. An important development in the Vedic medicinal practice was the use of an herbal formulation for the treatment [5].

Food is also said to be the major source that gives nutrition needs to our body but with the growing modernization, we forget some of the traditional ways because of the working population and changing lifestyle where we get less time to think about our health and wellness. Ayurveda is one of the oldest healing systems exciting from the last 5000 years old. An ideal nutritious diet is derived from a variety of fresh foods consumed. Everything that is eaten is absorbed by five senses like Mouth, Nose, ear and skin, eyes. When we consume healthy and nutritious food it gives us long life and youthfulness. The right food with the correct proportion of food is vital for an individual. Most of the illness reported is due to the improper method of cooking and preparation. For example, apples have both astringent and sweet tastes whereas turmeric at the same time is astringent, bitter, pungent, and a little sweet. The taste of Oranges is both sour and sweet. And, within a type or category of food, individual items may have different qualities [6].

The World Health Organization (WHO) has declared the coronavirus disease 2019 (COVID-19) a pandemic. On 31st December 2019, a cluster of cases of pneumonia of unknown cause, in the city of Wuhan, Hubei province in China, was reported to the WHO. In January 2020, a previously unknown new virus was identified, subsequently named the 2019 novel coronavirus, and samples obtained from cases and analysis of the virus genetics indicated that this was the cause of the outbreak. This coronavirus was named corona-virus disease 2019 (COVID-19) by WHO in February 2020. The COVID-19 is an infectious disease caused by a newly discovered coronavirus. Most people infected with the COVID-19 virus will experience mild to moderate respiratory illness and recover without requiring special treatment. Older people and those with underlying medical problems like cardiovascular disease, diabetes, chronic respiratory disease, and cancer are more likely to develop serious illness. The best way to prevent and slow down transmission is to be well informed about the COVID-19 virus, the disease it causes, and how it spreads. At this time, there are no specific vaccines or treatments for COVID-19.In India, a majority of people rely upon traditional Indian medicine to treat human maladies due to less-cost, easier availability, and without any side-effect. These medicines are made from herbal plants. This study aims to assess the Indian herbal plants in the pursuit of potential COVID-19 inhibitors using in silico approaches [7].

\section{TURMERIC}

Turmeric, also known as Curcuma longais a member of the ginger family, Zingiberaceae. The Latin name is derived from the Persian word, "kirkum," which means "saffron," about the rhizome's vibrant yellow-orange color. It is indigenous to Southeast Asia, but has long been used and cultivated throughout India. Turmeric is highly valuable for the influence it exerts on the digestive system and the liver. Plants of the genus Curcuma belong to Zingiberaceae/ Scitaminae family and are known for their high therapeutic potentials. Curcuma longaLinn. (Haridra), Curcuma aromatica Salisb. (Vana Haridra), Curcuma amada Roxb. (Amragandhi Haridra), Curcuma Angustifolia Roxb, Curcuma caesia Roxb(Kali Haridra), Curcuma zedoaria Rosc. (Zedoary) are known important species among the hundred species seen in different parts of the world.Turmeric is an ancient spice, a native of South East Asia, used from antiquity as a dye and a condiment. It is cultivated primarily in Bengal, China, Taiwan, Sri Lanka, Java. Peru. Australia and the West Indies. It is still used in rituals of the Hindu religion, and as a dye for holy robes, being natural, unsynthesized, and cheap. Turmeric is, in fact, one of the cheapest spices. Although as a dye it is used similarly to saffron, the culinary uses of the two spices should not be confused and should never replace saffron in food dishes. Its use dates back nearly 4000 years, to the Vedic culture in India where it was used as a culinary spice and had some religious significance. The name derives from the Latin terra merita, i.e "meritorious earth" referring to the color of ground turmeric which resembles a mineral pigment. Turmeric (Curcuma longa) has been used for 4,000 years to treat a variety of ailments. Several research studies have found that turmeric may help treat several illnesses. However, it is important to remember several facts when you hear news reports about turmeric's medicinal properties. First, many studies have taken place in test tubes and animals, and the herb may not work as well in humans. Second, some studies have used an injectable form of curcumin (the active substance in turmeric). Finally, some of the studies show conflicting evidence. Nevertheless, turmeric may have promise for fighting infections and some cancers, reducing inflammation, and treating digestive problems. Turmeric is widely used as a food coloring and gives Indian curry its distinctive flavor and yellow color. It is also used in mustard and to color butter and cheese. Turmeric has long been used in both Ayurvedic and Chinese medicine as an anti-inflammatory, to treat digestive and liver problems, skin diseases, and wounds. The curcumin in turmeric has been shown to stimulate the production of bile by the gallbladder. Curcumin is also a powerful antioxidant; antioxidants scavenge damaging particles in the body known as free radicals, which damage cell membranes, tamper with DNA, and even cause cell death. Antioxidants can neutralize free radicals and may reduce or even help prevent some of the damage they cause. Besides, curcumin reduces inflammation by lowering levels of two inflammatory 
Jyoti Prakash et al.,; Sch J App Med Sci, Jan, 2021; 9(1): 65-69

enzymes (called COX-2 and LOX) in the body and stops platelets from clumping together to form blood clots.It is a valuable home remedy for bronchial asthma. A teaspoon of turmeric powder with a glass of milk twice or thrice daily is very effective. It acts best on an empty stomach. Turmeric is a valuable intestinal antiseptic. The rhizome, its juice or dry powder, mixed in buttermilk or plain water is highly beneficial in intestinal problems, especially chronic diarrhea. It also helps prevent flatulence. About 20 drops of the juice of raw turmeric, mixed with a pinch of salt, taken first thing in the morning daily is considered an effective remedy for expelling worms. Turmeric, being rich in iron is useful in anemia. A teaspoon of raw turmeric juice, mixed with honey is taken everyday in the treatment of this condition. Turmeric is useful in the treatment of measles. Turmeric roots are dried in the sun and ground to a fine powder. This mixed with a few drops of honey and the juice of few bitter gourd leaves can be taken by those suffering from measles.Turmeric with its antiseptic properties is a useful remedy for chronic cough and throat irritations. Half a teaspoon of fresh turmeric powder mixed in $30 \mathrm{ml}$ of warm milk is very effective in these conditions. To prepare this milk is poured on a hot ladle with turmeric in it and boiled over a slow fire. In case of a running cold smoke from burning, turmeric can be inhaled. This increases the discharge from the nose and brings quick relief. Turmeric in combination with caraway seeds or ajwain is beneficial for cold in infants and children. A teaspoon of turmeric powder and a quarter teaspoon of ajwainis added to boiling water which is then cooled. About 30 $\mathrm{ml}$ of this decoction sweetened with honey may be taken thrice a day in treating such conditions. For treating sprains or the swelling caused by sprains, turmeric paste mixed with lime and salt can be applied with beneficial results.

\section{USES}

In both India and China, turmeric is considered to be a bitter digestive and a carminative. Also, it is used by Unani practitioners to expel phlegm or Kapha, opening out the blood vessels to improve blood circulation. It is incorporated into food items such as rice and bean dishes as turmeric helps to improve digestion and reduce gas and bloating in the body. It is a cholagogue, stimulating bile production in the liver and encouraging the excretion of bile via the gallbladder. This improvesthe body's ability to digest fats. Whereas in western cuisine the use of turmeric is limited and where it only forms the partof several spice mixtures and sauces;also used to impart a bright yellowcolortomustardpaste.

\section{HEALTH BENEFITS OF TURMERIC IN OUR DAILY LIFE}

1. It is a natural antiseptic and antibacterial agent, useful in disinfecting cuts and burns.
2. When combined with cauliflower, it has shown to prevent prostate cancer and stop the growthof existing prostate cancer.

3. It helps to prevent breast cancer from spreading to the lungs in mice.

4. May prevent melanoma and cause existing melanoma cells to commit suicide.

5. Reduces the risk of childhood leukemia.

6. Is a natural liver detoxifier.

7. May prevent and slow the progression of Alzheimer's disease by removing amyloid plaquebuildup in the brain.

8. May prevent metastases from occurring in many different forms of cancer.

9. It is a potent natural anti-inflammatory that works as well as many anti-inflammatory drugsbut without the side effects.

10. Has shown promise in slowing the progression of multiple sclerosis in mice.

11. Is a natural painkiller and cox-2 inhibitor.

12. May aid in fat metabolism and help in weight management.

13. Has long been used in Chinese medicine as a treatment for depression.

14. Because of its anti-inflammatory properties, it is a natural treatment for arthritis andrheumatoid arthritis.

15. Boosts the effects of chemo drug paclitaxel and reduces its side effects.

\section{TURMERIC: HEALING PROPERTIES}

Besides flavoring food, to purify the blood and maintain proper skin conditions which is probably the mostcommon use of turmeric in ayurvedic treatment.

1. The main organs where the turmeric was used for treatment are the skin, heart, liver, and lungs.

2. Turmeric is used for epilepsy and bleeding disorders, skin diseases, to purify the body, mindand to help the lungs expel kaph.

3. Turmeric helps to regulate the female reproductive system where it purifies the uterus andbreast milk whereas in male it purifies and builds semenwhich is counterintuitive for apungent bitter.

4. Turmeric also helps in curing of fever, diarrhea, urinary disorders, insanity, poisoning, cough, andlactation problems in general.

5. Turmeric is used for treating external ulcers, decreaseskapha and alsoused to remove mucus in the throat, watery discharges like leucorrhea,and any pus in the eyes, ears, or wounds, etc.

6. In ancient time, the ayurvedic cooking had an extensive use of turmeric is every preparation as it provided medicinal cure as a detoxifying agentfor the liver, helped in balancing the cholesterol levels, fought against allergies, helped to stimulate digestion, helped to boost the immunity and enhanced the complexion.

Activities of Turmeric include Analgesic, antibacterial, anti-inflammatory, anti-tumor, anti- 
allergic, antioxidant, antiseptic, antispasmodic, appetizer, astringent, cardiovascular, carminative, cholagogue, digestive, diuretic, stimulant, and vulnerary.

\section{Therapeutic uses of Turmeric}

Anemia, cancer, diabetes, digestion, food poisoning, gallstones, indigestion, IBS, parasites, poor circulation, staph infections, and wounds.

Traditionally, turmeric in a wide range of activities in ayurvedic treatment. In many studies, it has been reported that turmeric is used as a medicinal agent for diseases like anti-inflammatory, anti-tumor, immunological effects, wound healing, anti-fungal, anti-oxidant, anti-microbial, anti-diabetic, anti-platelet, and mosquito repellent from wild turmeric. It is used for preventing andtreating coronary heart disease, epilepsyas an anti-allergic and as an auto-immune disease. The extracts from the turmeric roots are used for the treatment of cholecystitis, biliary calculi, and other related diseases. The ethanol extraction from the roots alsoexhibits a potent to the anti-angiogenic and pro-apoptotic effects in the mice bearing ehrlich ascites tumor cells in themwhereas the methanol extraction showed an anti-proliferative activity against the human cancer cells. It also shows thevitro estrogenic activity in the cells. The rhizomes yield showed $6.1 \%$ in the oil extract that exhibited an anti-tumor activity. The extracted oil is thenused in the treatment ofcervix cancer whereas the volatile oil exhibited in vivo inhibitory effect on the proliferation of hepatoma in mice. The essential oils that have been exhibited invitro-anthelmintic activity showed variousreported activities that include anti-microbial and anti-tumor activities of essential oil, anti-inflammatory activity [8].

\section{DIRECTION FOR USAGE}

It is recommended that 400 milligrams of a curcumin extract should be taken three times a day along with 445 milligrams of a standardized supplement for 2 to 3 times a day and 1tsp of the dried herb in a cup of warm milk daily. Simultaneously, the dosage of 1tsp to 1tbsp of the extract should be divided into several dosages over a day,or $1 / 8$ to $1 / 4$ tsp of turmeric tincture should be taken 3 times a day. It is preferred that an individual should intake the extract with an adequate amount of black pepper to have the medication appropriately. According to research, it has been seen that the usage of pepper with turmeric helps to improve the ability of the human body naturally.Ginger is also a good companion with turmeric.

\section{CAUTION}

Intake of turmeric is avoided incase if the victim has any bile duct obstruction. It has been seen that people with gallstones should take proper consultation from an herb physician, before using. It has been observed that the high dosage of curcuminoids would result in ulcersor cancer that will affect the reduction of $\mathrm{RBC}$ and $\mathrm{WBC}$ in the body. Therefore, while purchasing turmericalways keep in mind to buy from a good seller or form a good turmeric producer as some species are toxic.

\section{FUTURE PROSPECTS}

For decades, Turmeric in Ayurveda has been implied for various biological applications. Although some work has been performed in several medicinal applicationsstill there has been no studies found regarding the drug development carried out in ayurvedic medication, whereas the extraction of curcumin has numerous medicinal effects and clinical usagethatcan be implemented only afterextensive research on its bioactivity, mechanism of action, pharmacotherapeutics, and toxicity studies. However, the availability of curcumin isin a pure form that shows an extensive approach for the biological activitieswhich would beeasier to help to develop new drugs from this compound after performing proper experimentation on several extensive studies on the mechanism of action and pharmacological effects. In these years, it has been seen that there is an increase in the enthusiasm for ayurvedic treatment for several diseases using natural products where the usage of turmerichas been a highly promising natural anti-oxidant and has provided a wide scope for treatment in the biological functions on various diseases. It is found that the novel drug is usedtosupply control on diseases that include such as carcinogenesis, and oxidative stress-induced pathogenesis.

\section{CONCLUSION}

From the study, we concluded thatCurcuma longabeing a medicinal plant has a wide range of biological activities that can be used for various treatments such as inflammation, wound, and microbial infections whichareassociated with conditions like diabetes, tumor, and cancerous growth, etc. The pharmacological potentials have been proven through the present researches thatrevalidate the traditional and ayurvedic concept of wild turmeric as a potent herb in diseases related to skin, cardiovascular, and respiratory systems. The oil extract from Curcuma aromaticserves as an important bio-resource of antioxidants for usage in the food industries. Therefore, it is a promising herb which is used in the cosmetic industry for several yearswhere traditional practices have been updated with an anti- melanogenic, anti-oxidative, and free radical scavenging profile added with anti-inflammatory and anti-tumor activity. Henceforth, it provides a wide area for research into the detailed pharmacological actions of this drug which has not been explored much in comparison to its utility.

\section{REFERENCES}

1. Goothy SS, Goothy S, Choudhary A, Potey GG, Chakraborty H, Kumar AH, Mahadik VK. Ayurveda's Holistic Lifestyle Approach for the 
Management of Coronavirus disease (COVID-19): Possible Role of Tulsi. International Journal of Research in Pharmaceutical Sciences. 2020 Mar 20;11(SPL1):16-8.

2. Srivastava A, Agarwal R, Chaturvedi TP, Chandra A, Singh OP. Clinical evaluation of the role of tulsi and turmeric in the management of oral submucous fibrosis: A pilot, prospective observational study. Journal of Ayurveda and integrative medicine. $2015 \mathrm{Jan} ; 6(1): 45-49$.

3. Sikha A, Harini A. Pharmacological activities of wild turmeric (Curcuma aromatica Salisb): a review. Journal of Pharmacognosy and Phytochemistry. 2015;3(5).

4. Chattopadhyay I, Biswas K, Bandyopadhyay U, Banerjee RK. Turmeric and curcumin: Biological actions and medicinal applications. CURRENT SCIENCE-BANGALORE-. 2004 Jul 10;87:44-53.

5. Krup V, Prakash LH, Harini A. Pharmacological activities of turmeric (Curcuma longa Linn): a review. J Homeop Ayurv Med. 2013;2(133):21671206.

6. Padma TV. Ayurveda, Nature, Outlook India, 2005; 436, 486.

7. Debjit Bhowmik C, Kumar KS, Chandira M, Jayakar B. Turmeric: a herbal and traditional medicine. Archives of applied science research. 2009;1(2):86-108.

8. Rajkumar RP. Ayurveda and COVID-19: where psychoneuroimmunology and the meaning response meet. Brain, Behavior, and Immunity. 2020 Apr 22. 